\title{
MRI evaluation of hepatic and cardiac iron burden in pediatric thalassemia major patients: spectrum of findings by $\mathrm{T} 2^{*}$
}

\author{
Samar M. Shehata, Mohamed I. Amin ${ }^{*}$ and El Sayed H. Zidan
}

\begin{abstract}
Background: Iron deposition distorts the local magnetic field exerting T2* signal decay. Biopsy, serum ferritin, echocardiography are not reliable to adjust iron chelation therapy. Quantified MRI signal decay can replace biopsy to diagnose iron burden, guide treatment, and follow up. The objective of this study is to evaluate the role of $\mathrm{T}^{*}$ in quantification of the liver and heart iron burden in thalassemia major patients. This cross-sectional study included 44 thalassemia patients who were referred to MRI unit, underwent T2* MRI.

Results: Twenty-one male (47.7\%) and 23 female (52.3\%) were included (age range 6-15 years, mean age $10.9 \pm$ 2.9 years). Patients with excess hepatic iron show the following: 11/40 (27.5\%) mild, (13/40) 32.5\% moderate, and (14/40) 35\% severe liver iron overload. High statistical significance regarding association between LIC and liver T2* $(p=0.000)$ encountered. Cardiac T2* values showed no relationship with age $(p=0.6)$.
\end{abstract}

Conclusion: $T 2^{*}$ is a good method to quantify, monitor hepatic and myocardial iron burden, guiding chelation therapy and prevent iron-induced cardiac complications.

Keywords: Thalassemia major (TM), Liver iron concentration, T2*

\section{Background}

Thalassemia major (TM) patients require regular blood transfusions which may lead to iron overload. Excess iron is accumulated in the liver, heart and endocrine organs. Intracellular free iron can cause tissue damage, leads to arrhythmias, heart failure accounting for $71 \%$ of deaths in TM patients [1-4].

Significant cardiac iron load can be encountered, although the hepatic iron concentration is kept low, an issue urges the need to quantify this burden, especially in a non-invasive manner in the pediatric age group [5].

Instead of measuring the serum ferritin level (a metalloprotein found in the cells) to take a tissue biopsy to diagnose iron overload, $\mathrm{T} 2 *$ can be used as a noninvasive method [6]. T2* is useful in tailoring the iron chelation strategies $[7,8]$.

\footnotetext{
* Correspondence: aasser2012@gmail.com

Diagnostic Radiology, Zagazig University, 3 Othman ben afan St, Zagazig City, Sharkia Governorate, Egypt
}

Assessing the $\mathrm{T} 2$ and $\mathrm{T} 2 *$ relaxation parameters is the gold standard in cases of iron overload. Iron is not directly imaged, instead, water protons are imaged so long they diffuse near iron deposits in the tissue of interest. Those iron particles with their characteristic ferromagnetic effects act as small magnets, destroying the homogeneity of the magnetic field in iron-laden tissues, so moving water protons significantly exhibit different magnetic momentum and desynchronized from each other. A consequence yields a black image by a rate proportional to the iron load $[3,4]$. The objective of this work is to evaluate the role of $\mathrm{T} 2 \%$ in detection and quantification of cardiac and hepatic iron concentration in pediatric TM transfusion-dependent patients.

\section{Methods}

Study design and population

This prospective cross-section study included 44 thalassemia pediatric patients from 6 to 15 years old. They were referred from the pediatric department to radiodiagnosis department from February 2015 to January 2019 after getting a local institutional review board (IRB) 
approval and informed consents from all patients' parents before the study.

Inclusion criteria were pediatric TM patients receiving a regular blood transfusion and iron chelation agent (Ferriprox). Cases of siderotic cardiomyopathy or have potential contraindications to MRI examination including claustrophobia, metallic objects, and pacemakers were excluded. Patients were subjected to MRI examination after thorough history taking (regarding patient's chelation regimen, serum ferritin level and echocardiographic findings).

\section{Patient preparation}

MRI examinations were done using a 1.5 Tesla superconducting magnet (Achieva, Philips Medical System, Best, Netherlands). Fasting and sedation were not needed prior to the exam. Respiratory triggering was applied to ensure minimal movement and lessen respiratory motion artifact. In cases of free-breathing, increased signal averaging number to 3 was used (instead of 1 at breath-holding technique).

\section{Scan protocol and parameters}

Cardiac gating MRI exam was performed in a supine position with head first using torso phased-array body coil. The field of view (FOV) extends from the carina caudally to the lower renal pole.

The MR protocol is as follows: time of exam is $25-40$ min including time spent on instructing the patients.

- 3-plane localizer. (Ensure the heart at the center of the field).

- Cardiac T2* (Table 1): scanned at 8 different echo times (TE 1.5, 4, 6.4, 8.8, 11.2, 13.6, 16, and $18.5 \mathrm{~ms})$.

- The following two sequences were used: single breath-hold multi-echo gradient echo sequence (white blood) and double inversion recovery "black blood' sequence where TI should be set to extend into diastole and the blood signal should be

Table 1 Parameters for cardiac T2* imaging

\begin{tabular}{ll}
\hline Parameter & Value \\
\hline Slice thickness & $10 \mathrm{~mm}$ \\
FOV & $40 \mathrm{~cm}$ \\
Flip angle & 20 \\
Matrix & $128 \times 256$ \\
TE & $1.5-18.5$ with 2.4 ms increments \\
TR & $99-125 \mathrm{~ms}$ \\
Bandwidth & $810 \mathrm{~Hz} /$ pixel \\
Flow compensation & On \\
Fat saturation & Off \\
\hline
\end{tabular}

adequately nulled thus reducing the blood flow artifact and motion artifact.

Mid ventricular imaging plane using 2 chamber, 4 chamber, and short-axis images (usually mid papillary muscle level) was selected not encroaching on the outflow tract. To minimize the breath-hold time we used in plane rotation and reduced the field of view in phase encoding direction.

Liver T2* (Table 2): the acquisition consists of 5 slices collected through the center of the liver in a single breath-hold at 16 different echo times (TE 1, 1.9, 2.7, 3.6, 4.4, 5.3, 6.1, 7, 7.8, 8.7, 9.5, 10.4, 11.3, 12.2 , and $13.1 \mathrm{~ms}$ ) with a gradient-echo sequence (Turbo field echo: TFE) to ensure accurate measurement of liver T2* in cases with light liver iron burdens.

We used large voxels to improve the signal to noise ratio and so decreased echo time. Voxels are 4-5 $\mathrm{mm}$ in-plane resolution. According to body habitus FOV was adjusted (FOV $<32 \mathrm{~cm}$ may prolong the echo time).

- Thin slice axial T2 (Table 3)*: provides a finer sampling of the entire abdomen extending from diaphragm dome to the lower renal poles. Slice positioning should have some slop to account for variable breath-hold position. Voxel size should have 2-3 mm in-plane resolution. It takes five stacks to span the target region. TR was reduced to increase coverage to five slices per breath-hold.

Before the patient's departure. The MRI technician must review the image data after scans are completed to avoid recalling the patient later for a repeat MRI.

\section{Image analysis}

Patient data were removed automatically from the DICOM meta-data by Image Inbox prior to image transfer. All MR images were sent to an advanced

Table 2 Parameters for liver T2* imaging

\begin{tabular}{ll}
\hline Parameter & Value \\
\hline Slice thickness & $10 \mathrm{~mm}$ \\
\#Slices/\#slices per BH & $5 / 5$ \\
FOV $(F \times$ Ph) & $40 \times 24$ \\
Flip angle & 20 \\
Frequency matrix & $96-128$ \\
Phase matrix & $64-96$ \\
TE & $1-13.1$ ms with 0.9 ms increments \\
TR & $100 \mathrm{~ms}$ \\
Bandwidth & Min water-fat shift \\
Pulse sequence & $810 \mathrm{~Hz} /$ pixel \\
\hline
\end{tabular}


Table 3 Parameters for axial T2* imaging

\begin{tabular}{ll}
\hline Parameter & Value \\
\hline Slice thickness & $5 \mathrm{~mm}$ \\
\#Slices/\#slices per BH & $15-25 / 5$ \\
FOV $(\mathrm{F} \times \mathrm{Ph})$ & $32-36 \times 24-27$ \\
Flip angle & 20 \\
Frequency matrix & $96-128$ \\
Phase matrix & $64-96$ \\
TE & $1-13.1 \mathrm{~ms}$ with 0.9 ms increments \\
TR & $100 \mathrm{~ms}$ \\
Bandwidth & Min water-fat shift \\
Pulse sequence & 810 Hz/pixel \\
\hline
\end{tabular}

workstation (Philips MR extended workspace, software version 2009). The data sets were typed to liver and heart spreadsheets. The $\mathrm{T} 2 \%, \mathrm{R} 2 \%$ LIC, and MIC were automatically calculated from the datasets [9-13] included in the analyses. Heart and liver plot charts were generated and final results were represented in colored manner based on the severity of iron burden; while green refers to normal values, mild affection is presented in yellow, moderate in orange, and severe in red color. All images were checked and analyzed by two radiologists (who were blinded regarding the laboratory, clinical situation of the patient and echocardiography results) as follows:
- Cardiac MR-T2* values were quantified with the region of interest in the ventricular septum to avoid susceptibility artifact. The region of interest was copied automatically to identical positions on images from different TEs (Fig. 1). Patients with iron-loaded heart showed rapid signal loss with increasing TE with both black and white blood sequences and T2* measures were less than $20 \mathrm{~ms}$. They were categorized as mild (15-20 ms), moderate (10-15 ms), and severe (T2*; < $10 \mathrm{~ms})$ [14].

- Myocardial iron concentration (MIC) was also calculated from R2* using the equation $(0.0254 \times$ $\mathrm{R} 2 *)+0.202(\mathrm{R} 2 *$, the reciprocal of T2*, 1000/T2*), according to carpenter JP et al. formula [15] where values from 1.16 to 1.65 indicate light, 1.65 to 2.71 indicate moderate, and more than $2.71 \mathrm{mg} / \mathrm{g}$ indicate severe cardiac siderosis.

- Liver-T2* values below $11.4 \mathrm{~ms}$ indicate iron overload: mild (3.8-11.4), moderate (1.8-3.8), and severe ( $>1.8 \mathrm{~ms})$.

- Liver iron concentration (LIC) using Garbowski MW et al. formula [16] was calculated where 2-7 $\mathrm{mg} / \mathrm{g}$ indicates light, 7 to 15 indicate moderate, and $<15 \mathrm{mg} / \mathrm{g}$ severe iron burden.

\section{Echocardiography}

It was performed within 1 week from MRI by a pediatric cardiologist who was blinded to the clinical data and imaging results to evaluate the cardiac function owing to
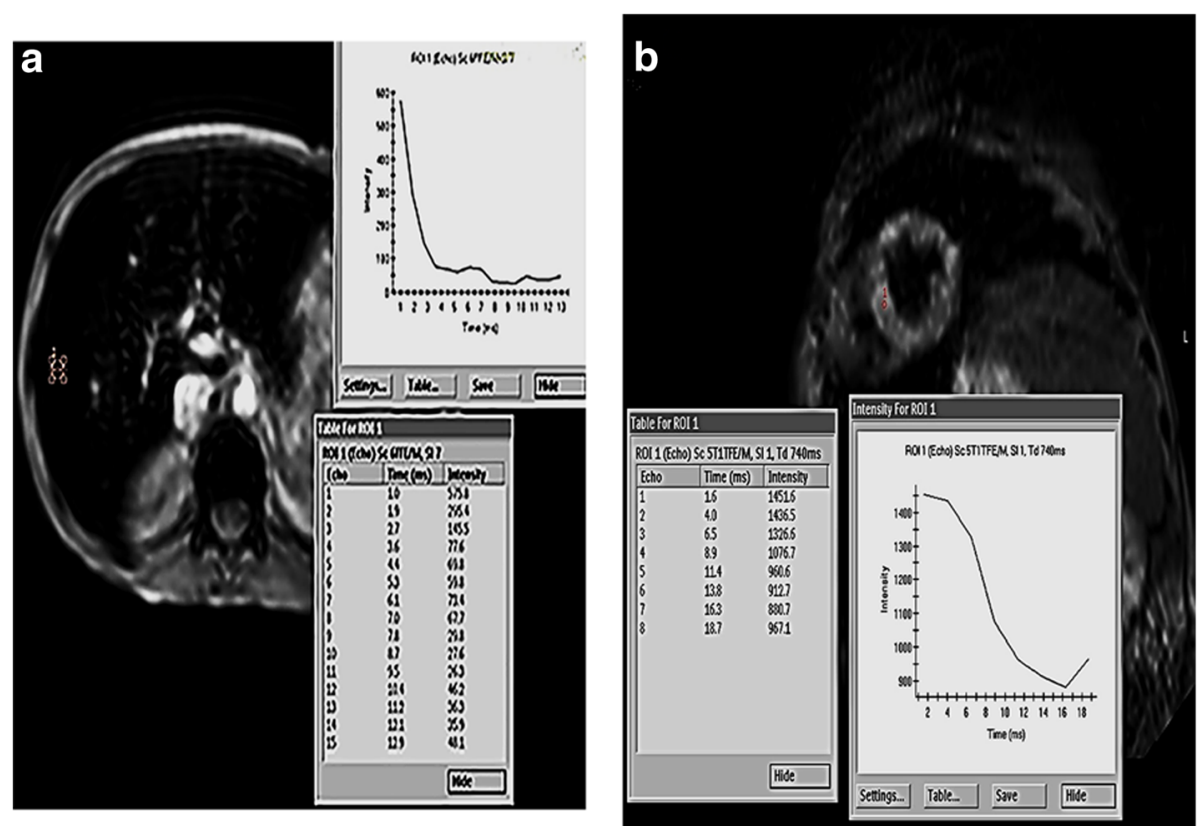

Fig. 1 Time-signal intensity curves delivered from ROI positioned in the right liver lobe (a) and interventricular septum (b) at 15 different TE (1.112.9ms) for the liver and 8 different TE (1.6-18.7ms) for the heart 
Table 4 Correlation between serum ferritin, hepatic, and cardiac investigations of the studied group

\begin{tabular}{llll}
\hline Variable & \multicolumn{2}{l}{ Serum ferritin } & \\
\cline { 2 - 4 } & $r^{\xi}$ & $p$ & SIG \\
\hline Cardiac T2* & -0.1 & 0.4 & NS \\
MIC & 0.2 & 0.1 & NS \\
Hepatic T2* & -0.4 & $0.02^{*}$ & $\mathrm{~S}$ \\
LIC & 0.5 & $0.01^{*}$ & $\mathrm{~S}$ \\
\hline
\end{tabular}

NS not significant; $S$ significant

*Statistically significant $(p \leq 0.05)$

${ }^{\$}$ Spearman correlation

Both Hepatic T2* \& LIC have $p$ values $<0.05$ so both are statistically significant

the unavailability of MRI software for cardiac function assessment in our department. The parameters tested were diastolic and systolic functions. An ejection fraction $>55 \%$ and $>27 \%$ fraction shortening was considered as normal systolic function; while E/A ratio less than 1 was considered as normal diastolic function.

\section{Serum ferritin level}

It was performed as a primary screening test to evaluate the iron overload.

\section{Statistical analysis}

The data analysis was performed using SPSS 20 (Chicago SPSS, SPSS Inc., Chicago, IL). Comparison of cardiac $\mathrm{T}^{*}$, MIC, and hepatic $\mathrm{T}^{*}$ and LIC values was performed with Kruskal-Wallis test. We used the Spearman test to correlate between serum ferritin level and $\mathrm{T} 2$, MIC, and LIC. A $p$ value of $<0.05$ reflects a statistical significance.

\section{Results}

This study included 44 pediatric TM patients (21 male; $47.7 \%$ and 23 female; $52.3 \%$ ). Only 40 (18 males; $45 \%$ and 22 females; 55\%) patients performed cardiac MRI and completed the study, their age ranges from 6 to 15 years with a mean $10.9 \pm 2.9$ years. Remaining 4 patients were excluded due to poor quality cardiac images from motion artifact. All patients received Ferriprox as iron chelator agent.

All subjects had a high serum ferritin (ranging from 1000 to $7000 \mathrm{ng} / \mathrm{ml}$ ) with a mean $3141.2 \pm 1967.5$. Only $35 / 40$ patients performed echocardiography and all patients had normal or accepted echocardiographic results regarding the diastolic and systolic functions.

Table 5 Association between LIC and hepatic T2* in the studied group

\begin{tabular}{lllll}
\hline Variable & $\begin{array}{l}\text { Normal LIC } \\
\text { mean } \pm \text { SD }\end{array}$ & $\begin{array}{l}\text { Abnormal LIC } \\
\text { mean } \pm \text { SD }\end{array}$ & $\begin{array}{l}\text { Mann-Whitney } \\
U \text { test }\end{array}$ & $p$ value \\
\hline Hepatic T2* & $18.4 .1 \pm 1$ & $4.3 \pm 4.2$ & 6.9 & $0.001^{* *}$ \\
\hline
\end{tabular}

Table 6 Association between MIC and cardiac T2* in the studied group

\begin{tabular}{lllll}
\hline Variable & $\begin{array}{l}\text { Normal MIC } \\
\text { mean } \pm \text { SD }\end{array}$ & $\begin{array}{l}\text { Abnormal MIC } \\
\text { mean } \pm \text { SD }\end{array}$ & $t$ test & $p$ value \\
\hline Cardiac T2 $^{*}$ & $36.1 \pm 7.9$ & $13.9 \pm 2.9$ & 3.9 & $0.001^{* *}$ \\
\hline
\end{tabular}

Cardiac T2* values showed no relationship with age ( $p=$ $0.6)$. An 8-year-old female was the youngest who developed cardiac siderosis.

The mean hepatic T2* value of the cases was $5.2 \pm 4.3$ $(0.82-18.4)$ ms with a median of 2.9 ms. The mean LIC was $13.3 \pm 9.4(1.67-37.29) \mathrm{mg} / \mathrm{g}$ with a median of 10.7 $\mathrm{mg} / \mathrm{g}$. Only $5 \%$ of patients $(n=2)$ showed normal iron based on LIC and T2* results. Among 38 patients (95\%) with excess hepatic iron, 11/40 (27.5\%) had mild, 32.5\% moderate (13/40), and 35\% severe (14/40) liver iron overload. A high statistical significance was found regarding the association between LIC and liver T2* $(p=$ 0.000 ) that signify a strong statistical relationship between the LIC and the value of hepatic T2* (Table 4).

Although liver iron loading was moderate to severe in $95 \%$ of patients, heart iron content could still be normal in $90 \%$ cases $(36 / 40)$. The mean cardiac $\mathrm{T}^{*}$ was $34.6 \pm$ 8.8 (range 11.8-52.93, median 34.2) ms and the mean MIC was $0.65 \pm 0.41$ (range 0.23-2.21, median 0.53) $\mathrm{mg} / \mathrm{g}$. Based on heart T2* and MIC results, only $10 \%(4 /$ 40) of cases showed increased cardiac iron burden. The association of heart T2* with MIC showed a high statistical significance $(p=0.000)$ (Table 5).

No significant correlation was found between the level of serum ferritin and cardiac iron content based on T2* and MIC $(r=-0.1, p=0.4)$ and $(r=0.2, p=0.1)$, respectively. However, a significant mild positive correlation has been observed between the level of serum ferritin and liver iron loading based on T2* $(r=-0.4, p=$ $0.02)$ and LIC $(r=0.56, p=0.01)$ (Table 6).

A significant but weak correlation $(r=0.3)$ between liver and heart $\mathrm{T} 2 *(p=0.02)$ was found; however, no statistically significant correlation was found $(r=0.1)$ between MIC and LIC ( $p=0.5)$ (Table 7).

\section{Discussion}

Beta-thalassemia major is a hereditary genetic disorder of hemoglobin which leads to hemolysis; an effect makes

Table 7 Correlation between hepatic and cardiac investigations of the studied group

\begin{tabular}{llll}
\hline Variable & \multicolumn{2}{l}{ Hepatic T2* } & \\
\cline { 2 - 4 } & $r^{\xi}$ & $p$ & SIG \\
\hline Cardiac T2* & 0.5 & $0.01^{*}$ & $\mathrm{~S}$ \\
& & MIC & \\
LIC & $r^{\xi}$ & $p$ & SIG \\
\hline
\end{tabular}




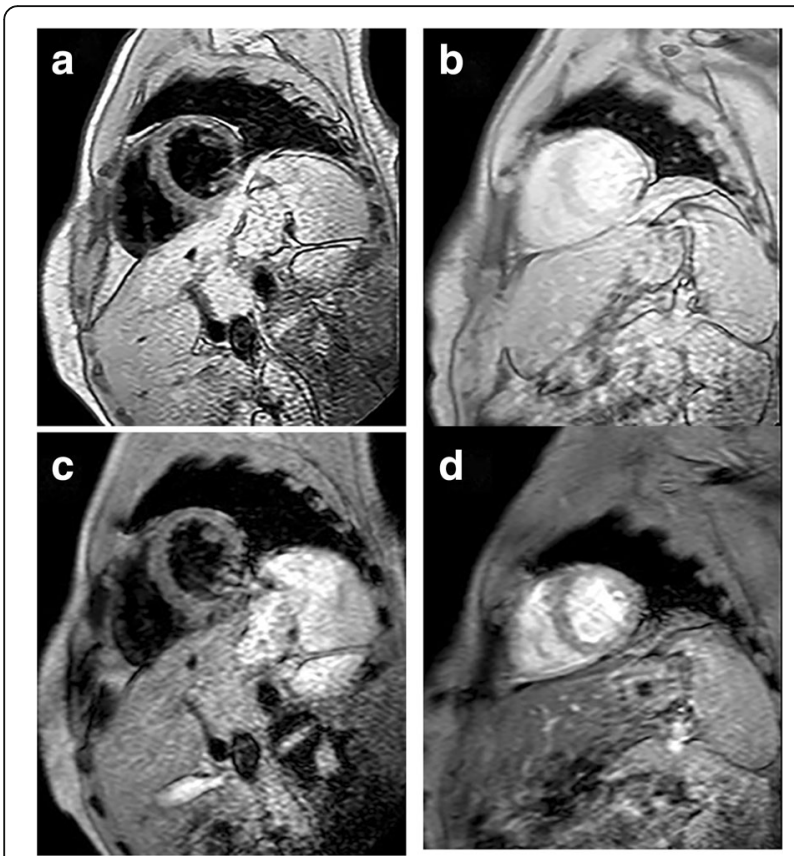

Fig. 2 Gradient echo black blood and white blood T2* static images acquired at TE $1.6 \mathrm{~ms}(\mathbf{a}, \mathbf{b})$ and TE $18.8 \mathrm{~ms}(\mathbf{c}, \mathbf{d})$ show no decay at $\mathrm{T}^{*}$ signals of the liver or the heart in a thalassemia major patient; normal values of the liver (T2* $18.4 \mathrm{~ms}, \mathrm{LIC} 1.67 \mathrm{mg} / \mathrm{g}$ ) and heart (T2* $50.4 \mathrm{~ms}$ and MIC $0.38 \mathrm{mg} / \mathrm{g}$ ). The measured serum ferritin was $2000 \mathrm{ng} / \mathrm{ml}$ consistent with normal liver and heart findings

these patients need repeated blood transfusions that lead to iron overloading including the liver, heart, spleen, bone marrow, pancreas, and endocrine system $[1,16,17]$.

Iron deposition in the heart follows a characteristic pattern; it is greater in the epicardium and more in the ventricles than the atria $[3,5,9,10,16,17]$. Cardiac dysfunction depends on the quantity of the deposited iron and the extent of fibers involvement. Despite the reversible nature of siderotic cardiomyopathy, the heart is still considered the target lethal organ as $71 \%$ of deaths in TM patients are caused by cardiac complications such as iron-induced acute myocarditis and acute heart failure [9-19].

The magnetic resonance signal of the hepatic and cardiac tissues depends on the $\mathrm{T} 1$ and $\mathrm{T} 2$ relaxation times (TR) of their iron content (Fig. 2). T2* is inversely related to intracellular iron, increased tissue iron displays a moderate decrease in $\mathrm{T} 1$ signals and extreme decrease in T2 signal intensities [10, 20, 21].

$\mathrm{T}^{*}$ is a simple, non-invasive and rapid technique that is gained in a single breath-hold $[1,8,9,11,14]$. Owing to the late development of the clinical findings and echocardiographic abnormalities, MR-T2* has become the strongest biomarker for simultaneous evaluation of liver and heart iron burden [1, 19] plus prediction of iron-induced cardiac complications such as heart failure and arrhythmia in TM patients [18-20].

Measuring serum ferritin level remains the primary screening test and is still used in monitoring the efficacy of chelation therapy. It has been reported that serum ferritin level greater than $2500 \mathrm{ng} / \mathrm{ml}$ is considered an important risk factor for developing ironinduced complications such as liver cirrhosis, heart failure, arrhythmias, impaired growth, and delayed puberty [22-25].

In this study, the level of serum ferritin ranged from 1000 to $7000 \mathrm{ng} / \mathrm{ml}$.

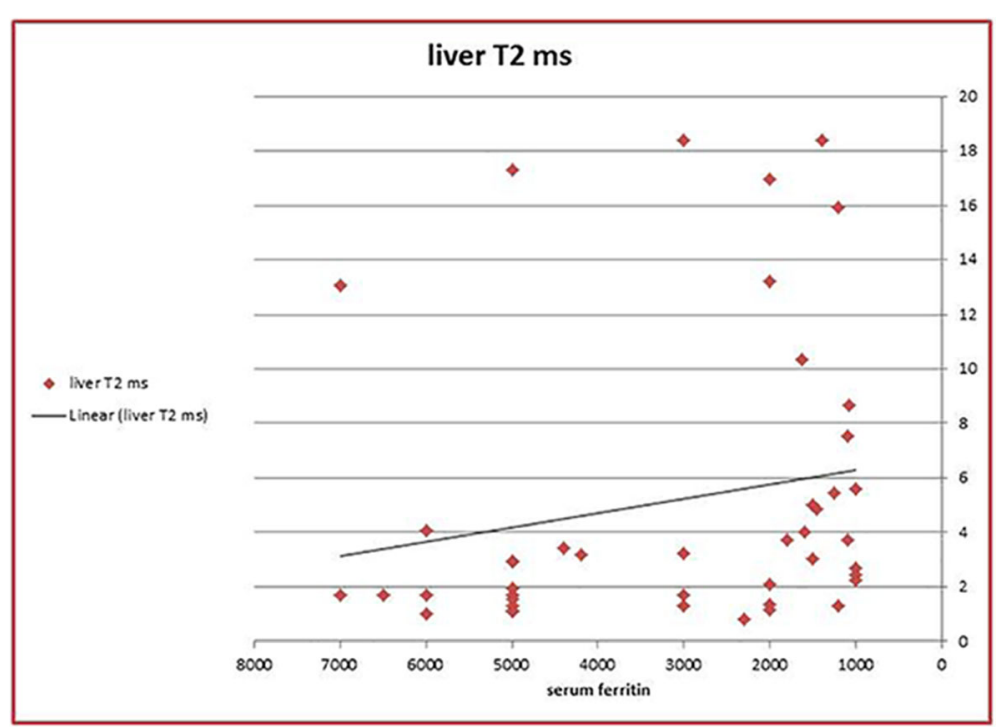

Fig. 3 Scatter plot with line chart for negative correlation between hepatic T2 and serum ferritin 


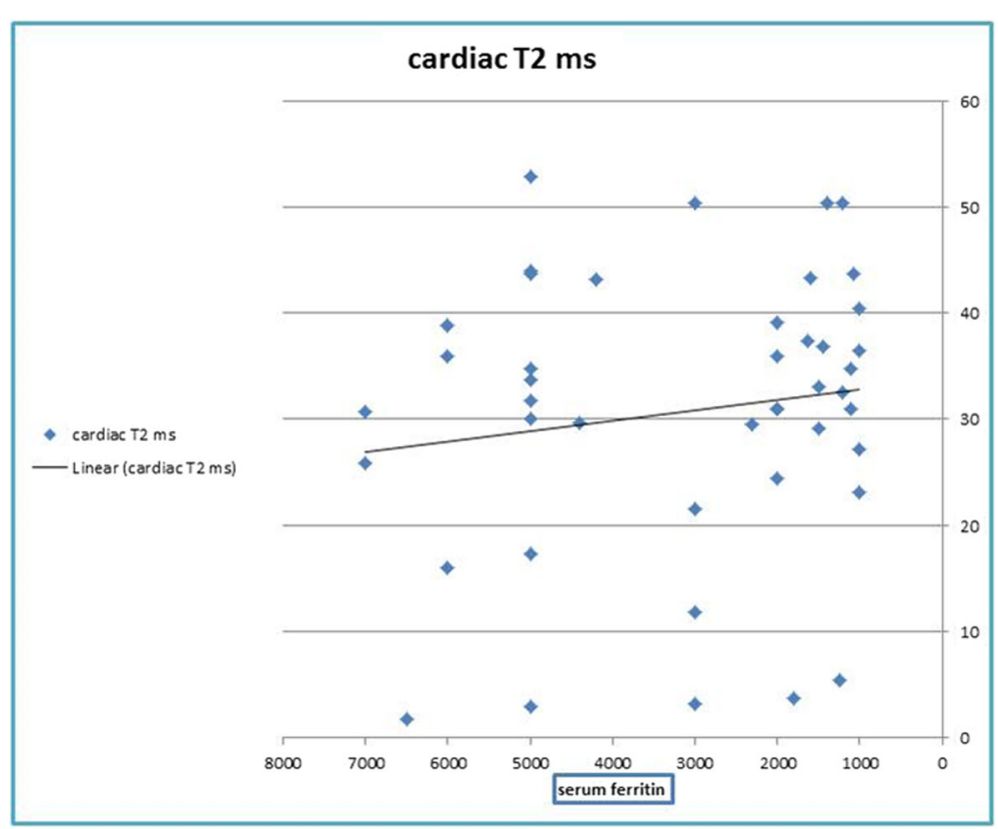

Fig. 4 Scatter plot with line chart for the correlation between serum ferritin and cardiac T2
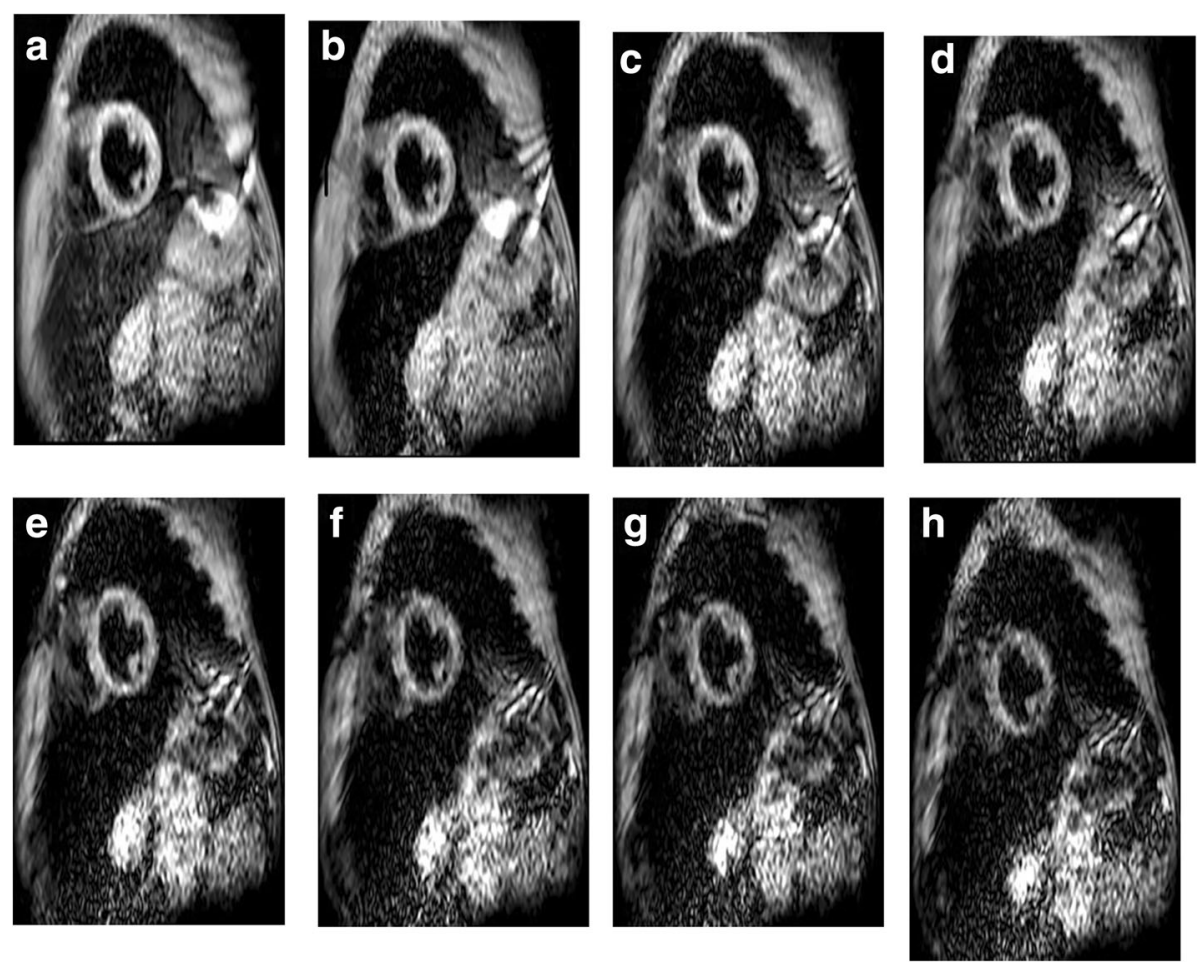

Fig. 5 Black blood static images of the liver \& heart acquired at different 8 echo times (1.6-18.7ms) reveals a significant decrement in liver signals with measured values of (T2*: $1.1 \mathrm{~ms} \&$ LIC: $28.91 \mathrm{mg} / \mathrm{g}$ ) and normal heart signals with normal (T2*: $43.9 \mathrm{~ms} \& \mathrm{MIC}: 0.45 \mathrm{mg} / \mathrm{g}$ ). The measured serum ferritin was $7000 \mathrm{ng} / \mathrm{ml}$. Findings are consistent with severe hepatic iron deposition with normal cardiac findings 
A significant mild positive correlation has been observed between the level of serum ferritin and liver iron loading (Fig. 3); however, no significant correlation was found between the level of serum ferritin and heart iron content based on T2* (Fig. 4), LIC and MIC (Table 4). Also Eghbali et al. [26] studied the association between liver and heart $\mathrm{T}^{*}$ and levels of serum ferritin in TM patients and he reported a correlation between serum ferritin level and liver $\mathrm{T} 2^{*}$, but not cardiac T2*. However, Puliyel M et al. 2014 [27] reported that ferritin cannot predict the total body iron changes with a little relevance between cardiac and hepatic iron content and levels of serum ferritin. Anderson et al. 2001 [21] also reported a nonsignificant correlation between cardiac $\mathrm{T} 2 *$ and levels of serum ferritin while Tanner et al. 2005 [7] reported a weak correlation between them.

Wood et al. 2005 [8] and Papakonstantinou et al. 2009 [9] reported that MR-R2* mapping could accurately estimate LIC in transfusion-dependent TM patients. Previous studies found that the frequency of MR-T2* relies on the iron concentration and chelation therapy used $[11-13,18]$. In this study, a high statistical significance was found regarding the association between LIC and liver T2* $(p=0.000)$ (Table 5) and between MIC and cardiac T2* $(p=0.000)$ (Table 6).
Previous literatures reported that cardiac $\mathrm{T} 2 *$ of $52 \pm$ $16 \mathrm{~ms}$ is the reference range and $20 \mathrm{~ms}$ is the minimum value for normal myocardium T2* [13]. Cardiac siderosis cannot be predicted from the hepatic iron load because liver iron normalizing within 3-6 months which is much faster than the heart $[12-14,18]$.

We found that although iron-loaded liver was detected in $95 \%$ of cases with moderate to severe affection in $67.5 \%(27 / 40)$ of cases, yet the myocardial iron was still normal in (90\%) of cases (Fig. 5). However, a significant but weak correlation $(r=0.3)$ has been observed between hepatic and cardiac $\mathrm{T}^{*}(p=$ $0.02)$. But no significant correlation was found $(r=$ $0.1)$ between MIC and LIC $(p=0.5)$ (Table 7). In agreement with our results, Anderson [12] reported that a marked discordance was observed between hepatic and cardiac iron concentration. Also Di Tucci et al. [28], Tanner et al. [29], Perifanis et al. [30], and Wood et al. [17] reported that no correlation was found among liver $\mathrm{T} 2 \%$, cardiac $\mathrm{T} 2 \%$, and iron concentration levels.

In this study, only $10 \%$ of studied cases $(4 / 40)$ developed iron-loaded heart with either mild $(5 \% ; n=$ 2) or moderate $(5 \% ; n=2)$ cardiac siderosis which is much less than those reported by Majd et al. [31]
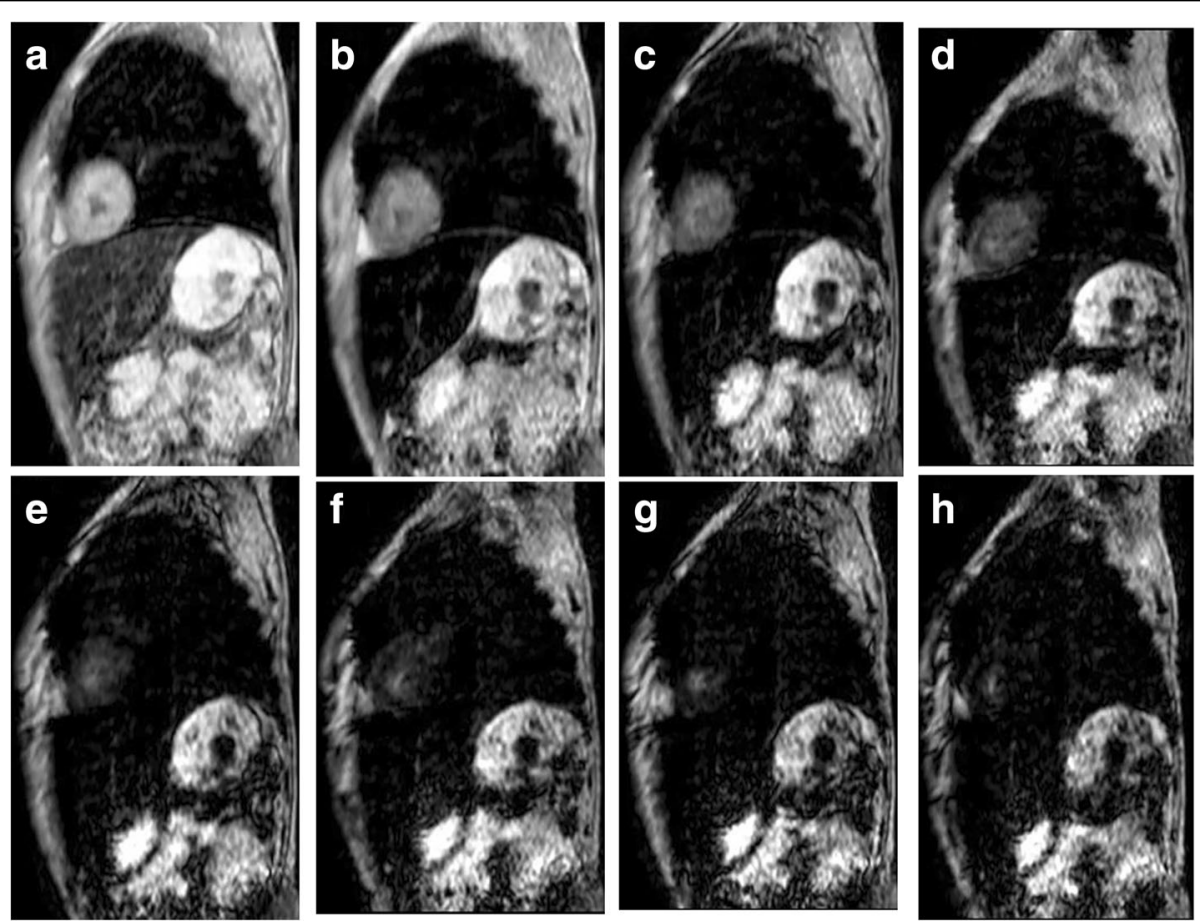

Fig. 6 Coronal images of the liver and heart at 8 different TE (1.6-18.7ms) reveal a significant decay in both hepatic and myocardial signal that increases on longer TE imaging sequences. The measured cardiac values were (T2*: value of $11.8 \mathrm{~ms}, \mathrm{MIC}: 2.21 \mathrm{mg} / \mathrm{g}$ ) and hepatic values were (T2*: $1.3 \mathrm{~ms}$, LIC: $25.33 \mathrm{mg} / \mathrm{g}$ ). The measured serum ferritin was $3000 \mathrm{ng} / \mathrm{ml}$. These findings are consistent with severe hepatic and moderate cardiac iron deposition. (Note: the moderate cardiac iron overload inspite of the lower level of serum ferritin and liver iron burden in this case compared to the previous case (Fig. 5) reflecting the incompetence among serum ferritin, liver iron burden and cardiac iron load 
and Leung et al. [32] who described abnormal cardiac MR-T2* findings in $58 \%$ and $50 \%$ of patients respectively. This may be attributed to the different chelation regimens used and a better efficacy of ferriprox in removing excess cardiac iron; however, further prospective RCTs on a larger number of patients are needed to confirm this hypothesis.

Josep et al. [33] stated that using echocardiography to measure the diastolic parameters can distinguish early cardiac involvement before the appearance of clinical signs of heart failure. In our study, $10 \%$ of cases had excess cardiac iron; however, they presented with normal echocardiographic findings.

Auger and Pennelle [20] reported that assessment of cardiac iron loading should be started between the age of 6 and 10 years and that cardiac siderosis may present at the age of ten by acute heart failure. In this study, the youngest subject who developed cardiac siderosis based on abnormal cardiac $\mathrm{T}^{*}$ results was an 8-year-old female (Fig. 6). No significant correlation was found between patient age and the development of hepatic or cardiac siderosis $(p=0.6)$.

This study faced some limitations: first lack of regular follow-up of the patients, second is the inability to perform functional cardiac analysis using MRI owing to unavailable software of the equipment to accomplish that task in our institution, third is the lack of reference standard. Also the large percentage of cases with liver iron overload detected in this study raises the need to re-evaluate the iron chelation strategy used.

Overall, myocardial iron assessment from the assessment of serum ferritin, liver iron, or echocardiography is not reliable enough to adjust the iron chelation strategy in TM patients with risk for cardiac siderosis.

\section{Conclusion}

T2* MRI is nowadays the method of choice to early detect, quantify and monitor the hepatic and myocardial iron burden and guiding the chelation therapy to prevent the iron-induced cardiac complications and reduce patients' mortality.

\section{Abbreviations}

TM patients: Thalassemia major patients; IRB: Institutional review board; FOV: Field of view; E/A ratio: Early (E) to late (A) ventricular filling velocity; R2*: The gradient echo (the inverse of T2*); TFE: Turbo field echo sequence; RCTs: Randomized clinical trials; LIC: Liver iron concentration; MIC: Myocardial iron concentration

\section{Acknowledgements}

We would like to express our gratitude to Dr. Dudley Pennell, Dr. John C. Wood, and Dr. Gillian Smith for their assistance in interpreting our findings and Dr. Ahmed Samir for supplying us with the liver and heart spreadsheets thus enabled us to interpret the results ourselves.

\section{Authors' contributions}

$\mathrm{Ml}$ carried out the study concept and design, participated in the sequence alignment, and drafted the manuscript. SM carried out the process of literature search. ZE participated also in the sequence alignment and participated in the design of the study. SM performed the statistical analysis. All authors read and approved the final manuscript.

Funding

Not applicable

Availability of data and materials

This prospective cross-section study included 44 thalassemia pediatric patients from 6 to 15 years old. They were referred from the pediatric department to radio-diagnosis department from February 2015 to January 2019.

\section{Ethics approval and consent to participate}

This study was approved by the Institutional Review Board (IRB) of Zagazig University. A written informed consent from all patients' parents before the study were filled and signed, which are also approved by the Institutional Review Board (IRB) of Zagazig University with reference number 3186.

\section{Consent for publication}

All patients included in this research gave written informed consent to publish the data contained within this study by their parent.

\section{Competing interests}

The authors declare that they have no competing interests.

Received: 12 July 2019 Accepted: 6 September 2019

Published online: 02 December 2019

\section{References}

1. Brittenham GM (2011) Iron-chelating therapy for transfusional iron overload. N Engl J Med 364:146-156

2. Ansari S, Azarkeivan A, Miri-Aliabad G et al (2017) Comparison of iron chelation effects of deferoxamine, deferasirox, and combination of deferoxamine and deferiprone on liver and cardiac T2* MRI in thalassemia maior. Caspian J Intern Med 8(3):159-164. https://doi.org/10. 22088/cjim.8.3.159

3. Borgna-Pignatti C, Cappellini MD, De Stefano P et al (2006) Cardiac morbidity and mortality in deferoxamine- ordeferiprone-treated patients with thalassemia major. Blood 107:3733-3737

4. Voskaridou E, Douskou M, Terpos E et al (2004) Magnetic resonance imaging in the evaluation of iron overload in patients with beta thalassaemia and sickle cell disease. Br J Haematol. 126:736-742

5. Fahmy HS, Khater NH\& Ahmed HM et al. Reassessing the value of MRI T2* in evaluation of hepatic and myocardial iron concentration: an institutional study. The Egyptian Journal of Radiology and Nuclear Medicine (2015) 46, 1085-1090.

6. Mavrogeni SI, Markussis V, Kaklamanis L et al (2005) A comparison of magnetic resonance imaging and cardiac biopsy in the evaluation of heart iron overload in patients with beta-thalassemia major. Eur J Haematol. 75:241-247

7. TANNER MA, WESTWOOD MA, GALANELLO R, PENNELL DJ (2005) Baseline findings of a CMR driven randomized controlled trial of iron chelation therapy in thalassemia major. J. Cardiovasc. Magn. Reson. 7:31-32

8. Wood JC, Enriquez C, Ghugre N et al (2005) MRI r2 and R2* mapping accurately estimates hepatic iron concentration in transfusion-dependent thalassemia and sickle cell disease patients. Blood. 106:1460-1465

9. Papakonstantinou AE, Economopoulos $\mathrm{N}$ et al (2009) Assessment of iron distribution between liver, spleen, pancreas, bone marrow, and myocardium by means of R2 relaxometry with MRI in patients with beta-thalassemia major. J Magn Reson Imaging 29:853-859

10. He T (2014) Cardiovascular magnetic resonance T2* for tissue iron assessment in the heart Quant. Imaging Med.Surg 4:407-412

11. Nienhuis AW, Griffith P, Strawczynski H et al (1980) Evaluation of cardiac function in patients with thalassaemia major. Ann N Y Acad Sci 344:384-396

12. Anderson $L J$ (2011) Assessment of iron overload with $T 2 *$ magnetic resonance imaging. Progress in Cardiovascular Diseases 54:287-294

13. PENNELL DUDLEYJ (2005) T2* magnetic resonance and myocardial Iron in thalassemia. Ann. N.Y Acad. Sci 1054:373-378. https://doi.org/10.1196/ annals.1345.045 
14. Kirk P, Roughton M, Porter JB et al (2009) Cardiac T2* magnetic resonance for prediction of cardiac complications in thalassemia major. Circulation 120:1961

15. Carpenter JP, Pennell DJ (2009) Role of T2* magnetic resonance in monitoring iron chelation therapy. Acta Haematol 122:146-154

16. Garbowski MW, Carpenter JP, Smith G, Roughton M, Alam MH, He T, Pennell DJ, Porter JB. Biopsy-based calibration of T2* magnetic resonance for estimation of liver iron concentration and comparison with R2 Ferriscan. J Cardiovasc Magn Reson. 2014 Jun 10;16:40. doi: https://doi.org/10.1186/ 1532-429X-16-40.

17. WOOD JC, TYSZKA TM, CARSON S et al (2004) Myocardial iron loading in transfusion dependent thalassemia and sickle cell disease. Blood 103: 1934-1936

18. Anderson LJ, Westwood MA, Holden S et al (2004) Myocardial iron clearance during reversal of siderotic cardiomyopathy with intravenous desferrioxamine: a prospective study using $T 2^{*}$ cardiovascular magnetic resonance. Br J Haematol 127:348-355

19. Wood JC (2007) Magnetic resonance imaging measurement of iron overload. Curr Opin Hematol 14:183-190

20. Auger D, Pennell DJ (2016) Cardiac complications in thalassemia major. Ann. N.Y. Acad. Sci 1368:56-64 C

21. Anderson LJ, Holden S, Davies B et al (2001) Cardiovascular T2* (T2 star) magnetic resonance for the early diagnosis of myocardial iron overload. Eur Heart J 22:2171-2179

22. Carpenter JP, He T, Kirk P et al (2014) Calibration of myocardial T2 and T1 against iron concentration. J. Cardiovasc. Magn. Reson. 16:62

23. Angulo IL, Covas DT, Carneiro AA et al (2008) Determination of ironoverload in thalassemia by hepatic MRI and ferritin. Rev Bras Hematol Hemoter. 30:449-452

24. Telfer PT, Prestcott E, Holden $\mathrm{S}$ et al Hepatic iron concentration combined with long-term monitoring of serum ferritin to predict complications of iron overload in thalassemia major. Br J Haematol.

25. Moussavi F, Ghasabeh MA, Roodpeyma S et al (2014) Optimal method for early detection of cardiac disorders in thalassemia major patients: magnetic resonance imaging or echocardiography? Blood Res. 49:182-186

26. Eghbali A, Taherahmadi H, Shahbazi M et al (2014) Association between serum ferritin level, cardiac and hepatic T2-star MRI in patients with major $\beta$-thalassemia. Iran J Ped Hematol Oncol:17-21

27. Puliyel M, Sposto R, Berdoukas VA et al (2014) Ferritin trends do not predict changes in total body iron in patients with transfusional iron overload. Am J Hematol. 89:391-394

28. Di Tucci AA, Matta G, Deplano S et al (2008) Myocardial iron overload assessment by $T 2^{*}$ magnetic resonance imaging in adult transfusion dependent patients with acquired anemia. Haematologica. 93:1385-1388

29. Tanner MA, Galanello R, Dessi C et al (2006) Myocardial iron loading in patients with thalassemia major on deferoxamine chelation. J Cardiovasc Magn Reson. 8:543-547

30. Perifanis V, Christoforidis A, Vlachaki E et al (2007) Comparison of effects of different long-term iron-chelationregimens on myocardial and hepatic iron concentrations assessed with $\mathrm{T}^{*}$ magnetic resonance imaging in patients with beta-thalassemia major. Int J Hematol. 86:385-389

31. Majd Z, Haghpanah S, Ajami GH et al (2015) Serum ferritin levels correlation with heart and liver MRI and LIC in patients with transfusion-dependent thalassemia. Iran Red Crescent Med J. 17:e24959

32. Leung AWK, Chu WCW, Lam WWM et al (2009) Magnetic resonance imaging assessment of cardiac and liver iron load in transfusion dependent patients. Pediatr Blood Cancer. 53:1054-1059

33. Josep R, Wahidiyat PA, Trihono PP et al (2012) Comparison of cardiac dysfunction in thalassemia major patients using deferoxamine or deferiprone as an iron-chelating agent. Paediatr Indones. 52:272-279

\section{Publisher's Note}

Springer Nature remains neutral with regard to jurisdictional claims in published maps and institutional affiliations.

\section{Submit your manuscript to a SpringerOpen ${ }^{\circ}$ journal and benefit from:}

- Convenient online submission

- Rigorous peer review

- Open access: articles freely available online

- High visibility within the field

- Retaining the copyright to your article

Submit your next manuscript at $\boldsymbol{\nabla}$ springeropen.com 